DOI:

URL:https://www.upoli.edu.ni/

\title{
La Falta de Reconocimiento como Límite de la Dimensión Subjetiva del Derecho de Acceso a la Justicia'
}

Recibido: 08.07.2020 / Aprobado: 25.08.2020
Por Carlos Alberto García Cabrera ${ }^{2}$ https://orcid.org/0000-0002-2536-7437

\section{Resumen}

Este artículo presenta una visión humana del derecho de acceso a la justicia, fundada en relaciones intersubjetivas entre el Estado y los/as ciudadanos/ as, a partir de relaciones recíprocas basadas en el reconocimiento, la inclusión y la participación igualitaria de todos y todas frente a una nueva forma de entender y comprender el concepto de acceso a la justicia, especialmente la reconceptualización de la dimensión subjetiva que conlleva la satisfacción en el acceso, uso, disfrute y exigibilidad de la justicia con sentido humano, coherente e integrador de la sociedad humanizando la forma de hacer justicia, concibiendo esta dimensión no solamente como la posibilidad de oponer los derechos de la población frente a los poderes públicos o al derecho de un recurso con las reglas del debido proceso, sino también integrando la aplicación que garantice que la decisión que se produzca, a través de cualquier proceso o procedimiento, satisfaga el fin para el cual fue concebido con un eje transversal vivo del elemento humano.

Palabras clave: Derecho de acceso a la Justicia, reconocimiento, igualdad, dimensión subjetiva.

\section{Abstract}

This article presents a human vision of the right of access to justice, based on intersubjective relations between the State and citizens, based on reciprocal relations based on the recognition, inclusion and equal participation of all a new way of understanding and understanding the concept of access to justice, especially on the reconceptualization of the subjective dimension that leads to satisfaction in the access, use, enjoyment and enforceability of justice with a human, coherent and inclusive sense of society humanizing the way of doing justice, conceiving this dimension not only as the possibility of opposing the rights of the population against the public powers or the right of a recourse with the rules of due process, but also integrating the application that guarantees that the decision that occurs, through any process or procedure, satisfies the purpose for which it was conceived gone with a live transverse axis of the human element. ${ }^{3}$

Key words: Right of Access to Justice, recognition, equality, subjective dimension.

\section{Introducción}

El presente documento guarda en sus líneas el propósito de que nos adentremos participativamente con la ética del reconocimiento por el otro y la imaginación moral-subjetiva-creativa del potencial humano, para visionar una forma diferente de entender el concepto del derecho de acceso a la justicia, como la suma de reivindicaciones que hacen posible el goce y disfrute no solamente del acceso a la justicia, sino de todos los derechos humanos interdependientes en la singularidad de cada caso concreto, presentado por las partes en el sistema de administración de justicia.

1 Este artículo también será publicado a finales del presente año 2020 por publicaciones UPEACE, y fue elaborado en el marco de la invitación de la University for Peace de la ONU al autor, como docente experto al Seminario Internacional sobre Acceso a la Justicia en América Latina. Correo: coordinacionimlk@upoli.edu.ni

2 El autor es Abogado y Notario Público. Educador en Derechos Humanos y Máster Internacional en Estudios de Paz, Conflictos y Desarrollo. Ha desempeñado cargos como Asesor Organizacional y Coordinador de Proyectos de Desarrollo, Educación y Capacitación en organismos nacionales e internacionales, también es catedrático universitario en temas de Cultura de Paz, Resolución de Conflictos, Derechos Humanos y Derecho Constitucional.

3 Traducción del autor. 
La justicia sin reconocimiento no es posible, tampoco concebir únicamente el desarrollo del goce de este derecho en su dimensión objetiva, se hace necesario e imperativo que la dimensión subjetiva del acceso a la justicia cobre mayor sentido, estimación y relevancia para entender el conflicto de la partes en la dimensión más profunda y humana con la que se puede lograr obtener la justicia; siendo además génesis de cualquier proceso jurisdiccional o administrativo, esta forma de comprender y hacer justicia sitúa al ser humano en el centro y fin de la responsabilidad del Estado, desarrollando la paz positiva en las sociedades contemporáneas.

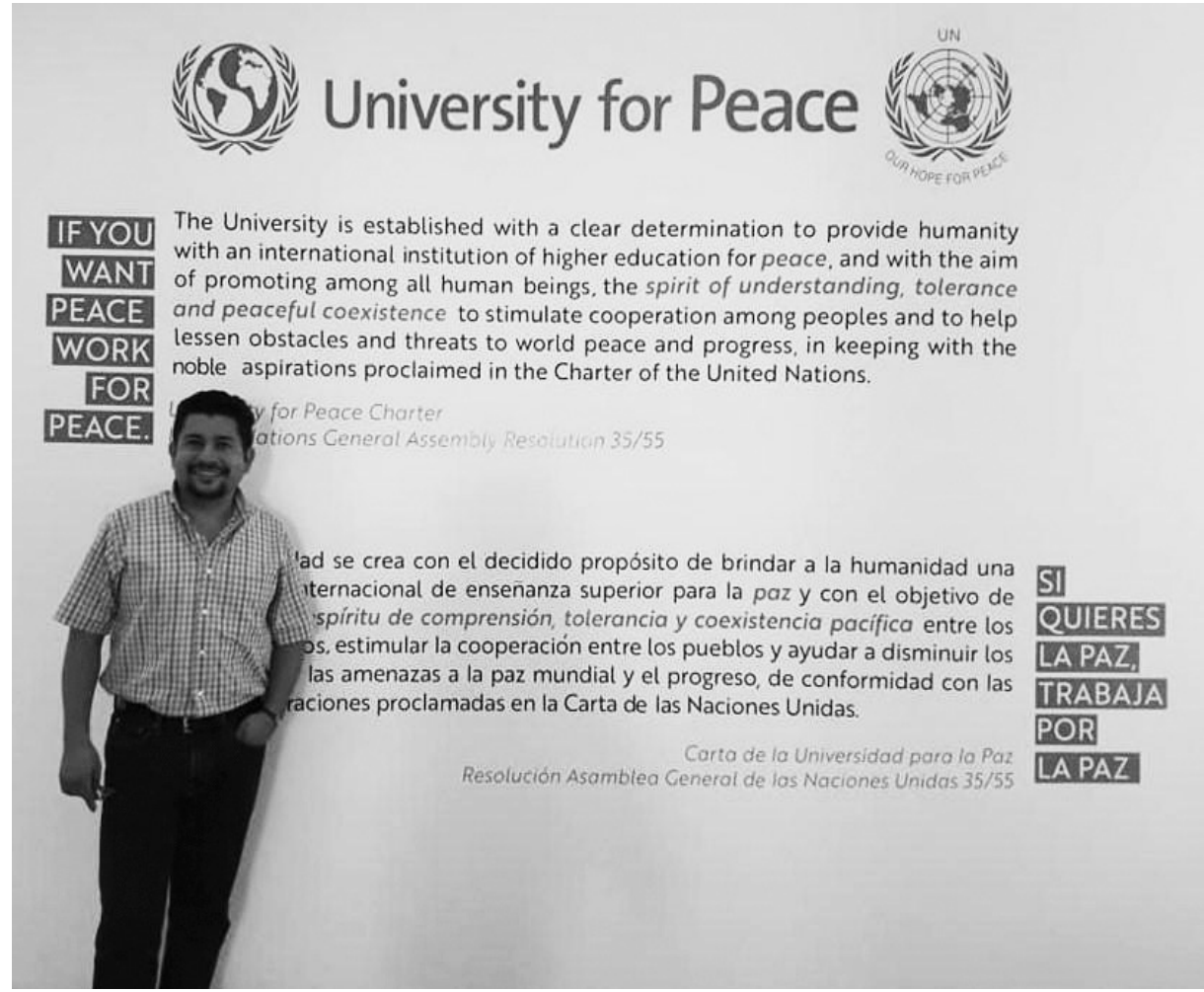

MSc. Carlos Alberto García Cabrera, en el Mural Central de la University for Peace de la ONU. Fotos propias del autor.
El documento presenta en un primer apartado los conceptos holísticos de acceso a la justicia y reconocimiento, y cómo la ausencia de este último genera la falta de acceso a la administración de justicia, producto de las desigualdades institucionalizadas en los sistemas judiciales.

En el segundo apartado, se analiza la trascendencia de la falta de reconocimiento en el derecho de acceso a la justicia, y la tendencia predominante de la dimensión objetiva sobre la dimensión subjetiva del derecho de acceso a la justicia.

En el tercer apartado, se presenta un aporte conceptual de la dimensión subjetiva del derecho de acceso a la justicia, que involucra el reconocimiento de las relaciones intersubjetivas entre el Estado y la Población, en una forma diferente de entender y hacer justicia. Al final, tras el análisis del material bibliográfico, se expone un comentario a manera de reflexión.

\section{Acceso a la Justicia y Reconocimiento}

Desde una perspectiva política internacional y nacional, el derecho de acceso a la justicia es un derecho humano inalienable que determina el deber del Estado de garantizar el acceso de todos y todas a la justicia, con equidad en la prestación del servicio. Implica que las decisiones de los órganos del Estado están sometidas a control jurisdiccional; y que comprende políticas públicas ${ }^{4}$ dirigidas a equilibrar el acceso a este derecho, a su educación cívica y humanista para el conocimiento y defensa del mismo en sistemas judiciales independientes, que han elegido rigurosamente jueces, magistrados y funcionarios probos, profesionales que aplican objetivamente normas, procesos y

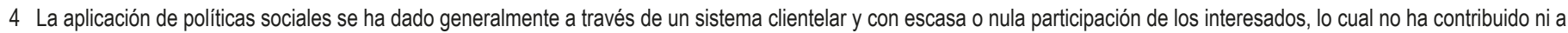
atacar de manera sustantiva la pobreza ni a fortalecer el ejercicio de la ciudadanía, lo que aliviaría, al menos en parte, las inequidades estructurales existentes. (R. Dahrendorf 1995, en: Calderón y Szmukler, 1997: 8) 
procedimientos con resultados transparentes, públicos, oportunos y accesibles. ${ }^{5}$

Este concepto ideal de acceso a la justicia que aún continúa en desarrollo en los sistemas judiciales, conlleva a seguir tratando a las personas objetivamente-, consecuentemente los resultados (sentencias y resoluciones) son objetivas, pero no responden a la satisfacción del sentido humano de la población que requiere de un trato intersubjetivo, que muestre un sentido interpelador, coherente e integrador de la sociedad que humanice -lo humano de la humanidad-, eso implica la perspectiva del sentido de participación y pertenencia de la población tanto a las normas que se aplican al caso concreto, como de la institucionalidad



Foto: Campus de la UPEACE/Carlos García Cabrera que las aplica, muestra de eso es la falta de confianza y uso menos frecuente de los sistemas de justicia.

El acceso a la justicia es un derecho fundamental, resultado de las reivindicaciones de la mayoría frente una minoría dominante que siempre ha poseído el poder político y económico, este derecho conlleva imprescindiblemente la igualdad ante la ley, la equidad social instituida en el aparato estatal que conduce al acceso, goce, uso, disfrute y exigibilidad del derecho tanto como una facultad inherente a la personalidad humana, como una prestación de servicio público de calidad y calidez con sentido humano y sin ningún tipo de discriminación, propiciando condiciones políticas, jurídicas, sociales y culturales de empoderamiento sobre su contenido, alcance y trascendencia en el acceso, promoción, ejercicio y defensa.

La falta de acceso a la justicia es producto de las desigualdades institucionalizadas en los sistemas judiciales ${ }^{6}$, debido a la falta de reconocimiento que provoca la indefensión, opresión, exclusión y empobrecimiento de la población, provocando que se pierda la estima social que une a los seres humanos a través del reconocimiento recíproco.

La falta de acceso a la justicia es un mal social, producto de las asimetrías entre los grupos sociales (mayoría-dominada y minoría dominante), que lesionan los derechos de igualdad y participación de la mayoría; al acceso y participación de la superestructura pública que para su existencia necesitó de sus cuotas de poder. ${ }^{7}$ La libertad individual de// otro/s fue reducida al mismo.

El término reconocimiento proviene de la filosofía hegeliana $y$, en concreto, de la fenomenología de la conciencia. En esta tradición, el reconocimiento designa una rela-

5 CJI/RES.187 (LXXX-0/12)

6 La violencia actualmente está institucionalizada socialmente y se fija como un modo de mantener el poder y la supremacía de algunos grupos. En este escenario la meta del poder es sujetar la subjetividad de los sujetos. (Jiménez, F. 2011)

7 Es el reconocimiento legítimo de quienes han cedido su cuota de energía por consenso en la construcción de una comunidad humana. El poder surge cuando hombres y mujeres actúan juntos y desaparece cuando se dispersan. (Arendt, H. 2005) 


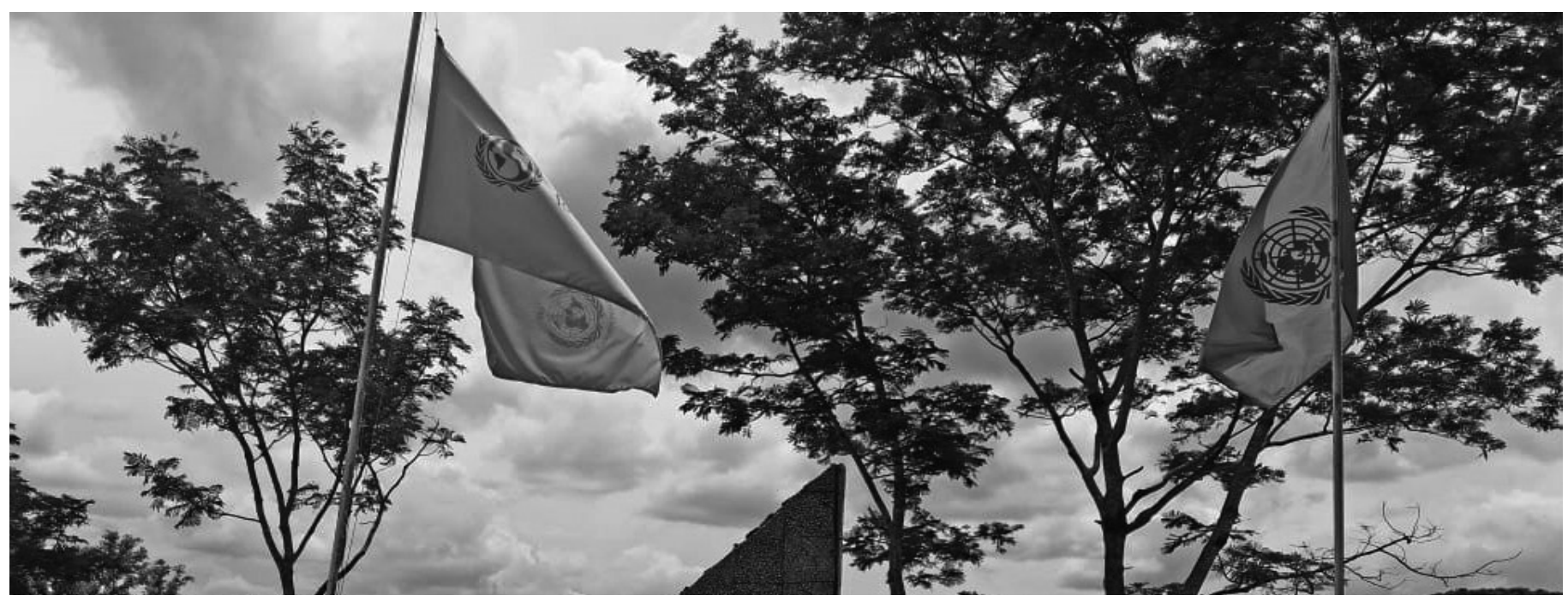

Foto: Campus de la UPEACE/Carlos García Cabrera

ción reciproca ideal entre sujetos, en las que cada uno ve al otro como su igual y también como separado de sí. Se estima que esta relación constitutiva de la subjetividad: uno se convierte en sujeto individual solo en virtud de reconocer a otro sujeto y ser reconocido por él. Por tanto, el reconocimiento implica la tesis hegeliana, considerada a menudo opuesta al individualismo liberal, de que las relaciones sociales son anteriores a los individuos y la intersubjetividad es anterior a la subjetividad. Es más, a diferencia de la redistribución, suele interpretarse que el reconocimiento pertenece a la ética, en cuanto opuesta a la moral, es decir, que promueve los fines fundamentales de la autorrealización y la vida buena, frente al derecho de la justicia procedimental. ${ }^{8}$

El reconocimiento sienta las bases de una sociedad humana, justa y pacífica que pone al ser humano en el centro y fin de su desarrollo humano sostenible, potencia capacidades afrontando retos y desafíos con unidad, identidad y sentido de pertenencia como miembros todos de un grupo humano. Todos somos uno; cada uno, una célula de ese cuerpo llamado humanidad. Cuando se tiene esta mentalidad universal, la persona se ve libre del odio que divide a la humanidad, y es incapaz de participar en la violencia?. El acto de herir a otro, con palabras o armas, es un acto de separación. Cuando uno sabe que está conectado con todo, no puede ni imaginar que golpee a otros, mucho menos sentir odio por pretendidos enemigos. (Dyer, 1997)

Justicia sin reconocimiento genera exclusión social, deslegitimación en las decisiones y resoluciones de los sistemas judiciales, acarrea desconfianza y la población disminuye el uso del sistema judicial por su burocracia, injusticia, desigualdad y parcialidad, a favor de un individuo o grupos de poder con mayores recursos e influencias, que podrían afectar la imparcialidad de la resolución y alcanzar esa justicia que los y las usuarios necesitan; por ejemplo, la débil tutela efectiva del derecho a la justicia sobre los derechos de propiedad, alimentos, estafas y acciones civiles y/o mercantiles relacionadas con instituciones bancarias y financieras con efectos incluso penales, empobrecen la sociedad.

El amor, el derecho y la solidaridad, constituyen formas de integración social en la que las personas son reconocidas recíprocamente

8 La teoría del reconocimiento está protagonizando en la actualidad por los filósofos neohegelianos, como Charles Taylor y Axel Honneth, están convirtiéndola en el eje de las filosofías sociales normativas que se proponen vindicar la política de la diferencia. (Fraser, 2006:85)

9 En este sentido, nos referimos a la violencia estructural del Estado en la negación de necesidades y en el establecimiento de obstáculos o trabas en sus estructuras que provocan la falta o limitaciones del acceso a la justicia. 
desde su individualidad. El amor entre las personas busca un bienestar del otro, en ese nivel los individuos se necesitan entre sí para sentirse realizados, dicha situación, al ser reconocida jurídicamente las relaciones de reconocimiento, se institucionalizan frente a toda la sociedad pudiendo ser exigibles y compelidas en un escenario de libertad e igualdad; que a través de la solidaridad las cualidades de las personas son valoradas, reconociéndoles un valor estimado con cualidades valiosas que distinguen a unos de otros. (Honneth, 1997: 114150). El reconocimiento dignifica el sistema de acceso a la justicia, humaniza su administración, al reconocer que tanto los operadores de los sistemas judiciales y usuarios son seres humanos y que ambos le dan un carácter humano a la institucionalidad que la representa.

El reconocimiento explica las violaciones que sufren los seres humanos, por un trato injusto, y consecuentemente que significa tratar a las personas con el mismo respeto e igual consideración.

\section{De la trascendencia de la falta de reconocimiento en el derecho de acceso a la justicia}

La tendencia predominante en América Latina es que el derecho de acceso a la justicia es un derecho fundamental que engloba o abarca diferentes derechos, tales como a recursos efectivos, la intervención de ley, la representatividad, garantías a un debido proceso, al mismo principio de legalidad, la publicidad de las normas, el acceso a la información, divulgación, la tutela y protección al recurso de pobreza, la creación de instituciones públicas gratuitas, tales como defensorías públicas o de oficio, facilitadores judiciales ${ }^{10}$; sin embargo, estas medidas y políticas aunque necesarias, adolecen del enfoque de la subjetividad, se les olvida que son creadas por y para seres humanos, que deben ser oponibles al poder estatal de sus poderes constituidos.

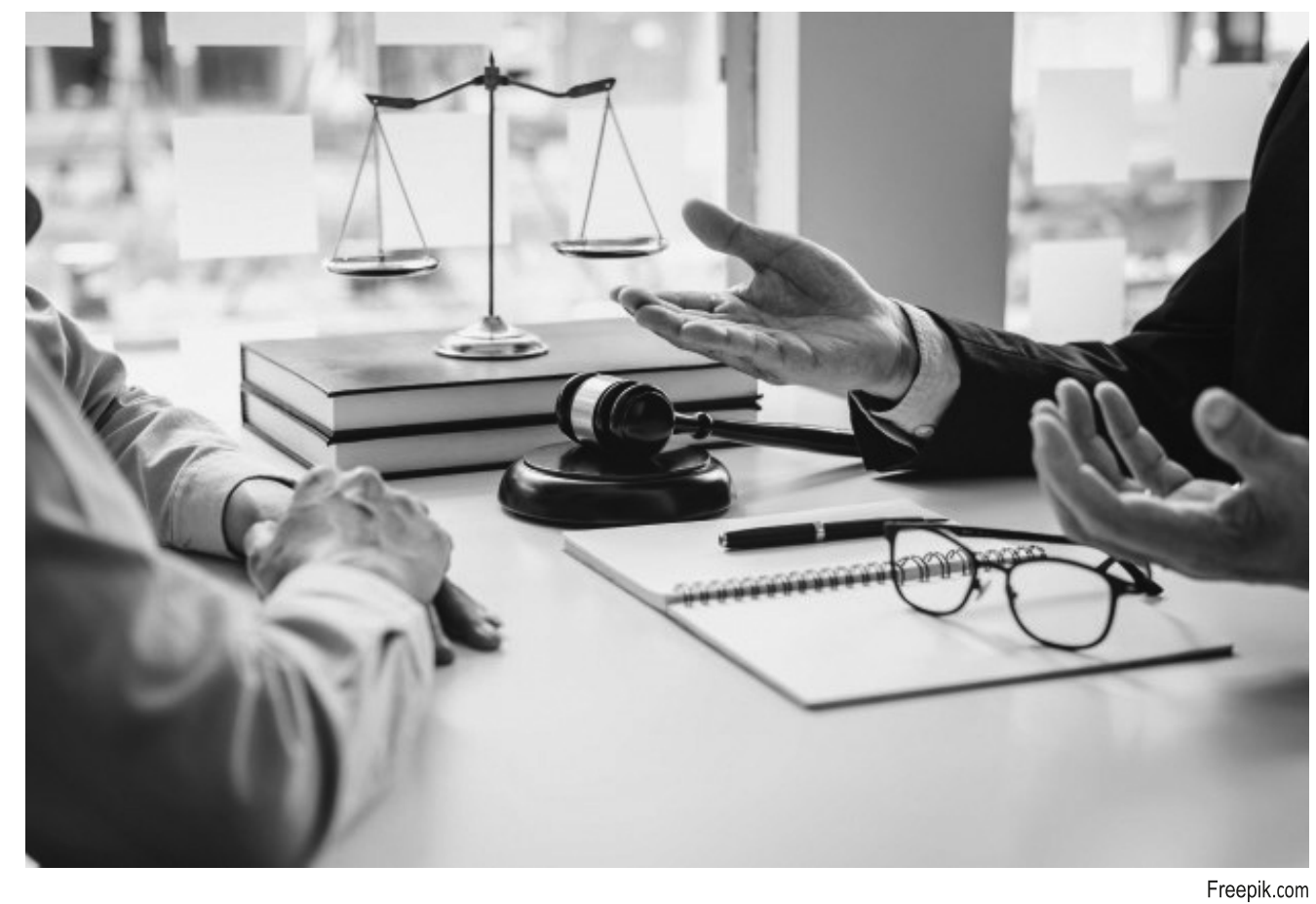

El Estado, usualmente utiliza sus recursos, elaborando políticas públicas de acceso a la justicia, implementando estrategias desde sus facultades jurisdiccionales de juzgar y ejecutar lo juzgado, pero no toma en cuenta el sentido de humanidad involucrando las necesidades de la población usuaria, supone que la justicia se basa en la mejora de procesos, procedimientos, inclusive cambios en sus estructuras, sin agregar elementos subjetivos propios que configuran -lo humano de la humanidad- de la cual también son partes los magistrados, jueces, funcionarios/

10 El derecho de acceso a la justicia. Un acercamiento al marco de referencia sobre su concepto, sus principios rectores, y su ámbito de protección. Documento UPAZ/GIZ 
as, operadores de justicia en general, como miembros de la sociedad humana.

El derecho de acceso a la justicia como derecho humano en sí mismo no puede ser apreciado y/o valorado únicamente en relación a la falta de condiciones instrumentales, estructurales, materiales, que impiden o limitan el acceso de la población al sistema de administración judicial, sino a la falta de espacios de participación de desarrollo de capacidades de la población, que no se realizan por la falta de reconocimiento del derecho humano de acceso a la justicia en los espacios legislativo, jurídicos, administrativos, afectivo y cultural, por los cuales no se realizan.

La falta de reconocimiento, afecta el acceso de la población al sistema de justica, como elemento de interacción e interrelación de la sociedad, las personas no lo sienten propio, ni suyo, un sistema judicial aislado del sentir ciudadano. Quiénes organizan y dirigen los sistemas de justicia, a través del poder judicial no son coherentes con las necesidades de los usuarios, ya que no los toman en cuenta en los procesos de elaboración. organización y cambio en ese sistema, producto del Estado como expresión máxima de la voluntad de la mayoría.

Cabe destacar en este sistema mundializado, el acceso a la justicia de quienes detentan el poder político y económico, inclusive organismos financiadores internacionales, son los únicos que deciden como debe administrarse la justicia. La población desconoce sus derechos, son vulnerables porque carecen del conocimiento para exigirlos, son fácilmente reprimidos y consecuentemente víctimas de violación a su dignidad, la exclusión institucionalizada esta legislada de tal forma, que no es visible para la población, quienes incluso son más fácilmente manipulados por las élites para lograr sus propios intereses. En este escenario de violación de derechos, también se rompe el Estado Social de Derecho.

El Estado actual en su dinámica, debe valorar y cambiar su perspectiva global, y reconocer que la metafísica de la identidad conduce a la exclusión, inclusive a la indolencia, reduciendo al otro en un espacio que lo hace invisible en un todo, excusa y argumento para la representatividad y tomar decisiones sin el otro, pero en detrimento de éste.

Reconocer al otro significa valorar su dignidad, sin seleccionar excluyendo, y que la perspectiva de los sistemas de justicia, no sea que los otros son lo que no es el Estado.

Cuando los sistemas judiciales utilizan su poder coercitivo en esta dinámica la subjetividad de las personas se vulnera, ya que, al haberse instaurado un sistema de acceso a la justicia sin la participación de la población como parte beligerante, el resultado es anular las diferencias individuales. Por el contrario, desde el enfoque del reconocimiento, el

Estado está fundado en la responsabilidad por el otro[s], como la suma de su propia existencia, quienes además le demandan y exigen máximas y mínimos para su autorrealización (derechos humanos), sin los cuales el Estado resultaría ser un simple fenómeno de fuerza y opresión.

La libertad de la población es responsabilidad del Estado, de reconocer su participación en él, a través de vínculos estrechos. El derecho de acceso a la justicia con reconocimiento descansa en la otredad entre el Estado y los otros, debe ser justo y bueno. El Estado debe ser replanteado como el espacio donde los seres humanos definen su propio sentido de justicia de vida buena. 


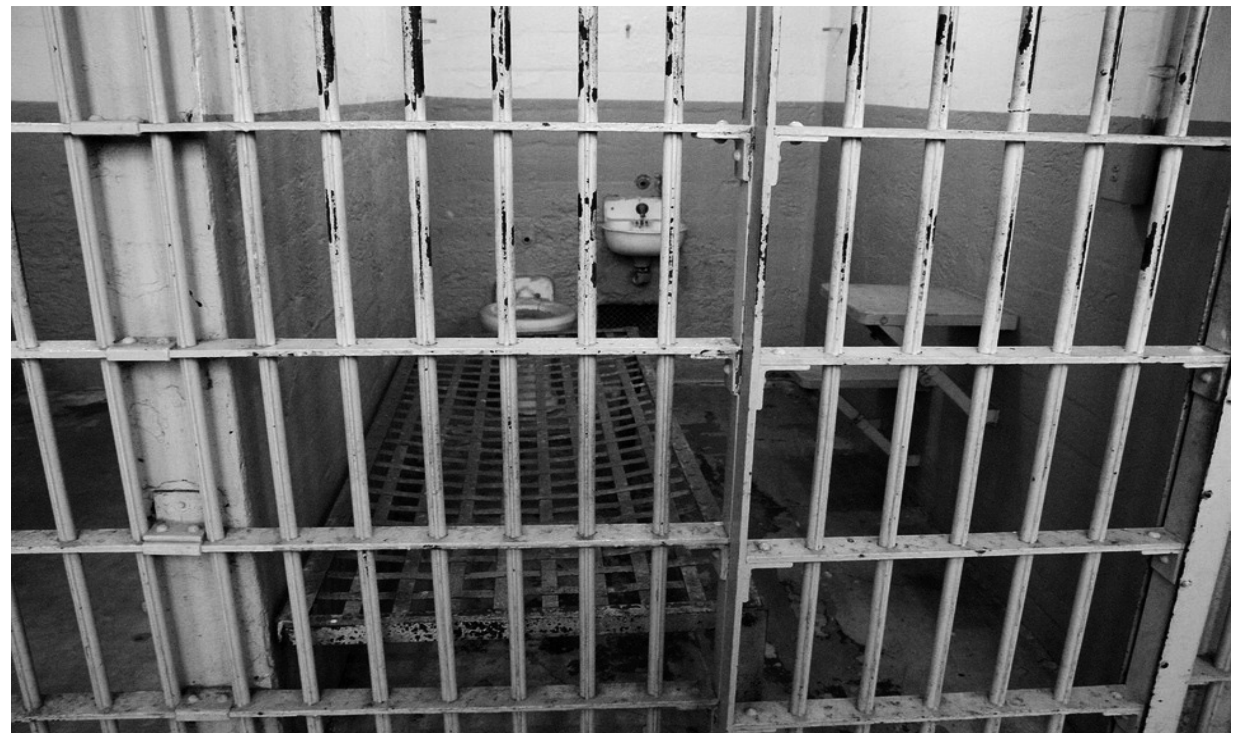

Pixabay.com

¿Son conocidos los principios generales rectores para la actuación estatal?

El conocimiento,
aprestamiento y ejercicio
de las ciencias jurídicas
y políticas ha estado
tradicionalmente en manos
de quienes han tenido la
capacidad económica
para sufragar estudios universitarios, generalmente en un principio los enriquecidos (terratenientes, políticos y empresarios), más adelante con la llegada de las revoluciones sociales que conllevaron medianamente

Frente a este panorama injusto, corregir la falta de reconocimiento significa, transformar los valores que regulan las instituciones, instrumentos, mecanismos y políticas públicas del derecho de acceso a la justicia, cambiando los valores que impiden la participación igualitaria de las personas. Cómo se realice esto exactamente dependerá, en cada caso, del modo en el que la falta de reconocimiento se haya institucionalizado.

Las formas jurídicas requerirán cambios legales, las formas políticas establecidas harán necesarios cambios políticos, las formas asociativas requerirán cambios asociativos, etcétera; tal y como ocurre en el entorno institucional, el modo y la forma de acción varían. No obstante, en todos los casos, el objetivo es el mismo: corregir las injusticas de reconocimiento supone reemplazar los modelos institucionalizados, que impiden la participación en igualdad de condiciones por otros que la permitan y favorezcan. (Fraser, 2000)

Las debilidades y falencias encontradas en el derecho de acceso a la justicia nos interpelan a hacernos preguntas, como base para encontrar juntos Estado y población, respuestas que nos lleven hacia una nueva forma de entender el sentido de justicia en la siguiente dirección: al acceso público de la educación universitaria, un sector más amplio empezó a involucrarse como activistas, movidos por el deseo de compartir ese derecho humano, al que aún pocos tiene acceso: la educación.

Esas son las bases para llegar a una conclusión real, que la educación en valores, civismo y en derechos humanos continua siendo un tema que aún no es del dominio público, ya que los principios que regulan la actuación estatal continúan siendo conocidos únicamente por quienes practican el derecho, generalmente la publicidad es poca y se da por conocido un nuevo material legislativo en la Gaceta, Diario Oficial, y desde ese momento es ley en los territorios donde se emite, sin embargo, el conocimiento del contenido de ese periódico oficial y de los derechos, libertades y garantías mínimos son material exclusivo de los abogados/as, quienes ejercen la defensa y promoción del derecho ó de los funcionarios públicos del sistema judicial; pero no de la población que esta desprovista de una educación básica de sus derechos civiles y políticos, son dependientes de abogados/as y del sistema judicial.

Le corresponde al Estado, dirigir la política de educación, pero por diversas causas (entre las que figuran las económicas, entre otras), no 
ha sido capaz de empoderar completamente o en otros casos de sostener a corto plazo, por sí solo, una educación para la paz, que conlleve a la generación de valores y cambios de actitudes en la población, por medio de la cual se desarrolle un estilo de ciudadanía real, diferente a la que tradicionalmente se utiliza cuando se aproximan elecciones presidenciales, dotando a la población del conocimiento de sus derechos y de las formas para exigirlos.

\section{¿Cuáles son las actividades idóneas para superar la situación?}

La falta de promoción de liderazgos inclusivos y participativos ha generado en los países latinoamericanos, fragilidad en la organización de las agrupaciones y eso tiende a debilitar sus estructuras y limita el acceso de las mismas al Estado, en ese sentido la falta de participación produce desconfianza, un alejamiento de las ideologías, lo que puede producir mayores dificultades de gobernabilidad, fragilidad en las mayorías, en especial de la juventud, en los sistemas de justicia y en los poderes del Estado, generando menos posibilidades de producir más cambios. ${ }^{11}$ La forma idónea para superar esta situación es a través de la educación y formación de la población en los instrumentos, mecanismos, espacios de participación ciudadana, que los empodere del conocimiento del marco jurídico y político de ciudadanía, para exigir sus derechos frente al aparato estatal. Es conveniente que la población organizada elabore con el Estado, una política de educación para una cultura de paz, que permita que la población acceda a la satisfacción de sus necesidades de acceso a la justicia, a través de la autogestión.

El escenario más propicio para hacer esto es lo local, como espacio más cercano de las familias a las estructuras políticas tomadoras de decisión, y por medio de la cual podemos incidir primariamente en la transformación de las necesidades de las personas, trabajando en conjunto con las mismas por el desarrollo de sus comunidades, a través del trabajo



Pixabay.com

11 Encuesta realizada por Latinobarómetro un estudio anual de opinión pública que se realiza desde 1996 en diferentes países de América Latina, el Poder Judicial figura entre las cuatro instituciones en las que menos confían los ciudadanos del continente. En 2017 tiene un promedio de $25 \%$, con Costa Rica en primer lugar con el $43 \%$, seguido de Uruguay con $41 \%$. Los países con la más baja confianza en el poder judicial son Paraguay con $15 \%$ y Perú con 18\%. Encontramos 15 de los 18 países que tienen una confianza inferior al 30\%. Disponible en: file://C:/Users/ MARIO/Downloads/F00006433-InfLatinobarometro2017.pdf 
comunitario que genere modelos participativos comunitarios, que permitan y favorezcan, la participación de todos y todas en las decisiones de sus gobiernos locales.

Es necesario que las instancias de educación formal y no formal, participen en estos procesos de educación a todos los niveles, a través de proyectos educativos que acerquen la universidad a las comunidades, apoyándolos en sus acciones, planes y actividades de desarrollo comunitario.

Se debe fortalecer las organizaciones no gubernamentales en los programas y proyectos de formación que lleven a cabo, fortaleciendo sus procesos organizativos, en relación a los proyectos destinados a mejorar la calidad y los niveles de acceso a la justicia de la población, a través del empoderamiento de la población en las metodologías, técnicas y herramientas que fomenten la auto gestión de sus demandas y necesidades de justicia, y transformando la actitud en la noción de conflicto y violencia, el primero como algo natural en las relaciones sociales, positivo porque que se convierte en experiencias pedagógicas de concientización, estímulo y desarrollo de la creatividad; y la violencia como un producto evitable de la cultura.

¿Será necesario reunificar la multitud de políticas públicas sobre acceso a la justicia para realzar el porqué de la existencia del derecho de acceso a la justicia?

No se trata de reunificar, sino de retroalimentar lo que ya tenemos, las experiencias, obstáculos y limitaciones y replantear un nuevo paradigma del derecho de acceso a la justicia que contenga el elemento humano, incluir el reconocimiento como eje fundador de una política de estado sólida y consensuada, que sea una política conjunta Estado y población, inclusiva y abierta que ponga al ser humano en el centro, y que tenga como fin y propósito, la satisfacción verdadera de justicia de quienes tienen un conflicto que no puede ser transformado por las mismas partes y se requiera de la intervención del sistema judicial, con enfoque humano y reparador.

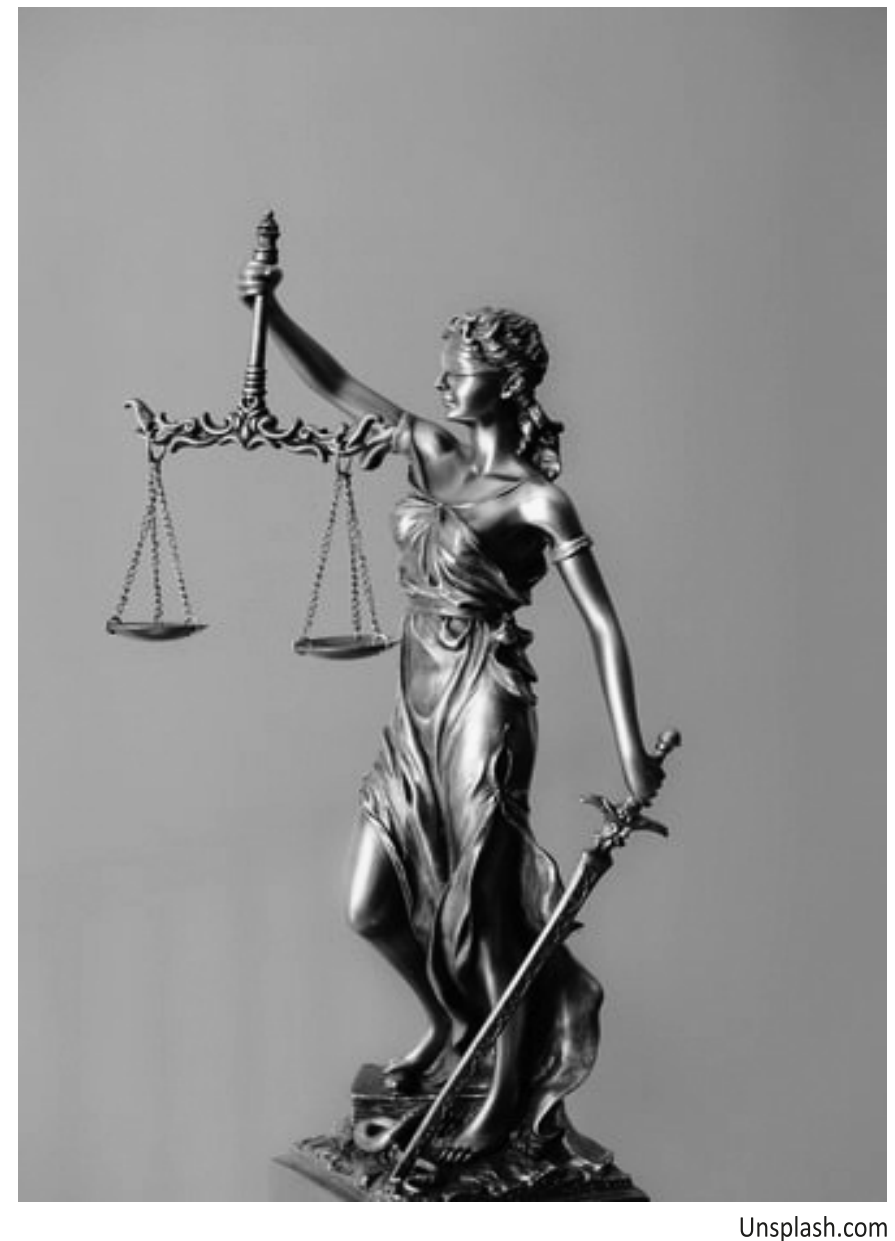

Hacía una reconceptualización de la Dimensión Subjetiva del Derecho de Acceso a la Justicia

La administración de justicia debe garantizar el principio de legalidad; protegiendo y tutelando los derechos humanos y garantizando el acceso a la justicia, mediante al menos el control de la legalidad, mediante instituciones como la Jurisdicción de lo Contencioso-Administrativa, para examinar la legalidad ordinaria en las demandas y/o recursos de tipo general o de tipo particular, que presenten los administrados en contra de todos los actos, resoluciones, disposiciones generales, omisiones o simples vías de hecho de la Administración Pública. $Y$, por otro lado, el control constitucional, por medio de una justicia constitucional ágil, de fácil manejo y comprensión, que permita el 
control jurisdiccional de la Constitución y que fomente el acceso a la justicia constitucional a través de procedimientos sencillos y de fácil manejo que fortalezcan la seguridad jurídica en el ámbito constitucional.

La práctica ha sido potenciar la actividad estatal en el fortalecimiento de la dimensión objetiva, en asimetría con la dimensión subjetiva del derecho de acceso a la justica; debido que la producción legislativa no incluye la participación de la población, el sistemajudicial no es el resultado de un consenso ciudadano, participativo, deliberativo, cívico, constructor de ciudadanía; lo que a la postre lo hace ilegitimo, desconocido y no reconocido por sus destinatarios. La producción del marco legislativo del derecho de acceso a la justicia, debe ser la construcción participativa de procesos culturales que involucren a los diversos sectores de la población. Este enfoque generalizado y dominante de la vinculación objetiva del derecho de acceso a la justicia, ha sido medianamente eficaz para disminuir la violencia, cohesionar las familias, aportar al cambio de una cultura de violencia por una cultura de paz; ya que no es acceso a la justicia, sino acceso a un sistema de aplicación de normas y leyes, a través de instituciones, con el fin de obtener acceso a una solución posiblemente jurídica, pero no justa.

Este tipo de administración de justicia es solo una función estructural del Estado, la justicia en cambio es la virtud y atributo exclusivo de las partes. Partiendo de esta premisa subjetiva del acceso a la justicia, el rol del Estado es legitimador y fedatario público de la justicia.

El arto. $2 \mathrm{CADH}^{12}$ establece: Los Estados se comprometen a adoptar las medidas legislativas o de otro carácter que fueren



necesarias, para hacer efectivos los derechos y libertades de la convención. El problema radica en que no están involucrando el sentir y las necesidades de la población, en relación a las dinámicas del acceso a la justicia, es necesario contextualizarlas para que respondan al ejercicio vivo de la ciudadanía, de lo contrario, los Estados acumularán instrumentos jurídicos y políticas públicas inadecuadas y paliativas que no resuelven las necesidades de la población usuaria del sistema de justicia.

El Estado de Derecho es el medio para la promoción y protección del derecho de acceso a la justicia, cuando se vulnera el medio el derecho se quebranta y se vuelve incompatible, ya que ambos son inversamente proporcionales, y la constante de proporcionalidad inversa, es un estado democrático que garantiza la plena y libre participación de su población en la toma de decisiones políticas.

El enfoque limitado de la dimensión subjetiva piensa que el juez es independiente y existe como un derecho de los propios jueces, sin embargo, es necesario recordar que la

12 Convención Americana de Derechos Humanos 
investidura del juez existe porque deviene del poder soberano que reside en el pueblo y que su función debe responder a un derecho subjetivo de toda persona usuraria del sistema judicial, que ha legado en un contrato social su cuota de poder a un Estado, que se supone, elige sus jueces con los más altos niveles de probidad, humanismo, competencia y con méritos obtenidos en la defensa y promoción de los derechos, y no por intereses de partidos políticos de turno en la administración de justicia.

Este enfoque predominante de la dimensión objetiva se ha expandido porque aún los sistemas judiciales no han humanizado el acceso, goce y disfrute de la justicia, las normas no forman parte del consenso, aceptación y reconocimiento de sus destinatarios; las sentencias y resoluciones no incorporan los aportes, enfoques de la jurisprudencia de la Corte IDH, ni de los instrumentos diversificados de protección de los derechos humanos, aunque estos inclusive formen parte de sus constituciones políticas y consecuentemente de sus ordenamientos jurídicos, no lo hacen. El estado de derecho y los derechos humanos, le dan vida a la existencia del juez independiente, no a lo contrario.

Obtener justicia desde esta perspectiva objetiva es un reto inconquistable, el derecho no siempre es justo. Se debe repensar la forma en la que se administra la justicia, -si la justicia emana del pueblo-, se debe tomar muy en cuenta a este pueblo para diseñar un nuevo paradigma de acceso a la justicia, debe partir de las necesidades actuales de la población, de las dinámicas de relación de los grupos que conforman toda la sociedad y tener como fundamento sine qua non, el reconocimiento de la persona humana, protagonista de su sentido y concepto de justicia. Se deben replantear las condiciones de justicia y equidad social para administrar justicia, si continúan haciendo reformas y cambios en la administración de justicia únicamente por parte de quienes tienen el poder para realizarlas, excluyendo el consenso ciudadano no habrá justicia, sino insatisfacción de la población que no obtuvo de ese sistema de justicia una respuesta 0 solución no violenta a sus necesidades.

Darle una significativa importancia a la dimensión objetiva del derecho de acceso a la justicia en relación a la dimensión subjetiva, conduce por un lado, a una percepción aislada y poco congruente entre los fines del Estado como administrador de los bienes, recursos y servicios en la satisfacción de las necesidades de la población; y por otro lado, una acumulación de funciones y obligaciones rígidas que entiende el acceso a la justicia únicamente a una estructura solemne, burocrática, exigente, formalista y probablemente onerosa; enfocado a cumplir normas de procedimientos que se suponen tutelan y protegen los derechos que se invocan.

La dimensión subjetiva no puede ser concebida únicamente como la posibilidad de oponer los derechos de la población frente a los poderes públicos o al derecho de un recurso con las reglas del debido proceso, debe agrupar la aplicación que garantice que la decisión que se produzca a través de cualquier proceso o procedimiento satisfaga el fin para el cual fue concebido con un eje transversal vivo del elemento humano.

Para superar este enfoque materialista y objetivo es necesario volver al origen, eso significa reencontrarnos con el otro y reconocer que el trato en la administración de la justicia es -entre seres humanos-, seres vivos que sienten, que son el producto de una combinación compleja de pensamientos, emociones y sentimientos, es preciso que tanto las normas 
como los funcionarios y operadores de los sistemas de justicia estén capacitados para comprender empáticamente la dimensión del trato humano, y que la complejidad humana requiere de relaciones intersubjetivas y no objetivas.

Es imperativo y necesario replantearnos un nuevo paradigma de justicia en los estados democráticos, se debe incluir un enfoque epistemológico y holístico al derecho de acceso a la justicia, como una facultad inherente, inalienable y universal del ser humano, reconociendo que el pueblo es el soberano investido de fundamento ético, racional (poder político de participación) que posee la capacidad de generar su propia perspectiva ética y moral de justicia, legitimada en las estructuras del Estado, mediante la creación de sistemas de acceso a la justicia emanados desde y para las personas agrupadas en comunidades, y que a través de su inclusión y trabajo conjunto con las autoridades de los poderes del Estado, participen en la construcción de espacios políticos y jurídicos que les asegure el pleno ejercicio de su derecho de acceso a la justicia

En este nuevo modelo los derechos de acceso a la justicia en su complejidad son universales, interdependientes e indivisibles y

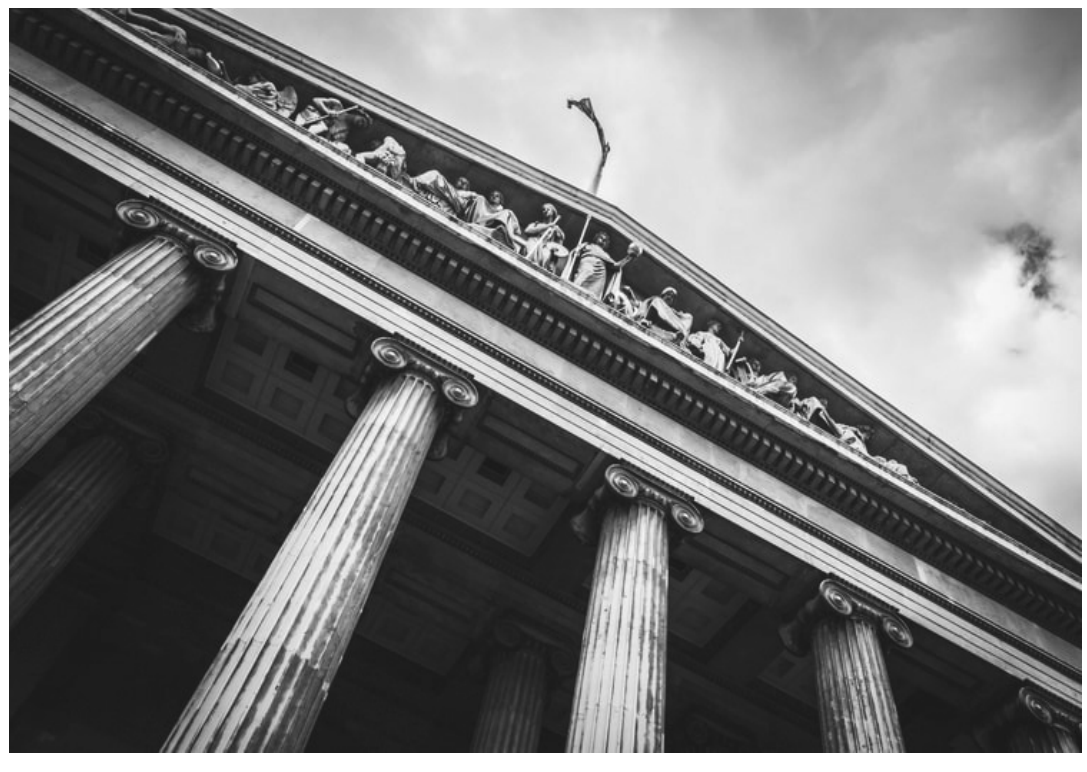

Unsplash.com corresponden a la persona como su principal eje y actor, no al Estado. Los protagonistas de la justicia son esas mismas personas que están haciendo uso de ese derecho humano, dignificados por la protección y plena vigencia de su derecho de acceso a la justicia y que están aportando a la construcción del Estado de Derecho, mediante el ejercicio de su propia ciudadanía; igualmente la dimensión subjetiva del acceso a la justicia está compuesta por el conjunto de derechos humanos, que facultan y permiten la protección individual y colectiva de la población frente al poder estatal y de personas particulares en el acceso al sistema judicial, su fundamento filosófico y jurídico está recogido al inicio de la Declaración de los Derechos Humanos, que reza así: "Considerando que el respeto a la dignidad inherente a todos los miembros de la familia humana y a sus derechos iguales e inalienables constituye el fundamento de la libertad, de la justicia y de la paz del mundo... los pueblos de las Naciones Unidas han proclamado de nuevo su fe en los derechos fundamentales del hombre, en la dignidad y el valor de la persona humana".

En este sentido, el Estado debe proveer las condiciones para el goce y disfrute del derecho de acceso a la justicia, estableciendo mecanismos que sean del conocimiento de la población, para su debida exigibilidad cuando ha sido violentado por este.

El cambio de paradigma de la dimensión subjetiva del derecho de acceso a la justicia involucra una marco político de participación ciudadana conformado ampliamente por todos los grupos, movimientos, partidos, organismos de la sociedad, sindicatos, etcétera; que representen una propuesta firme y consensuada de cómo hacer justicia frente al Estado, y por otro lado, la creación legislativa de un marco jurídico valido y eficaz que establezca los medios, mecanismos, procesos, procedimientos, acciones y derechos de las personas para 


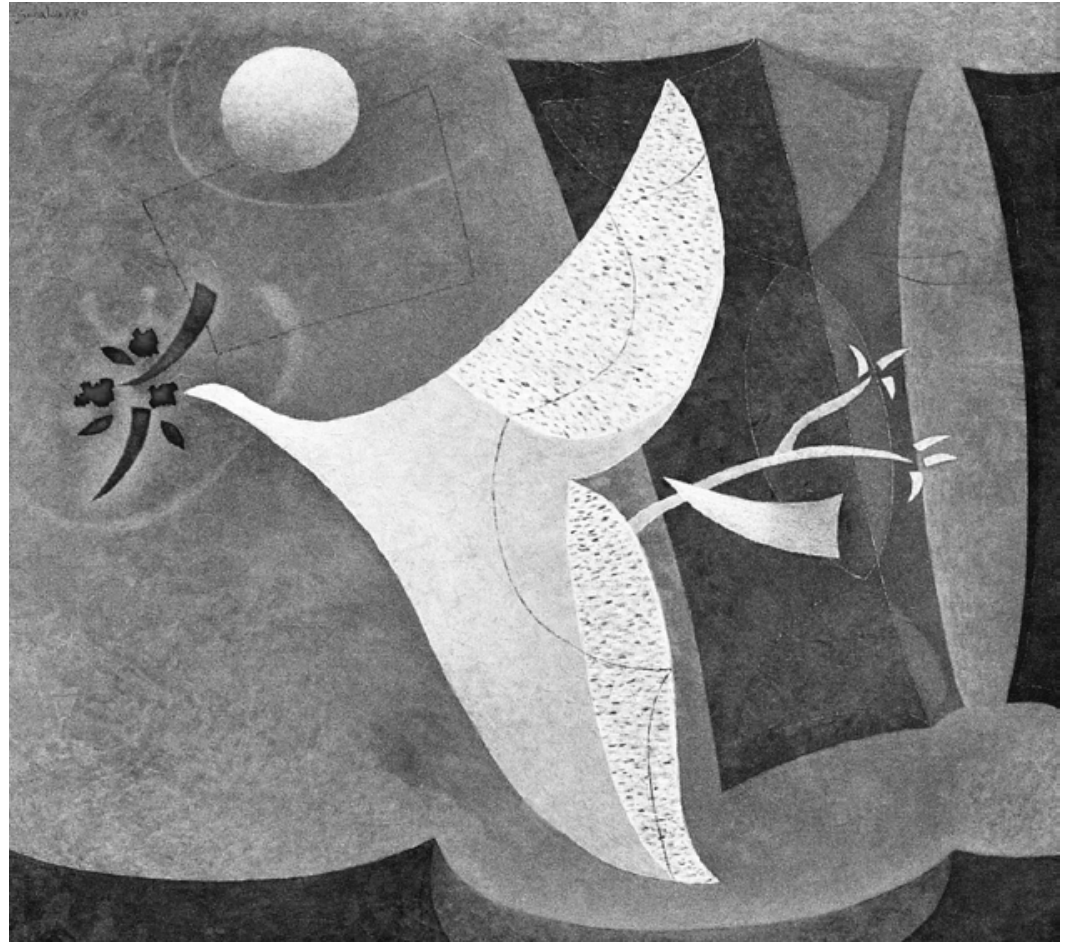

Autor: Orlando Sobalvarro. Título: Vuelo de Paz

protegerse del Estado en la vulneración de su derecho de acceso a la justicia.

En este nuevo paradigma de acceso a la justicia las expectativas de la población se hacen reales, (reconocimiento, participación, empoderamiento, empatía, sentido de pertenencia) a través del cambio de la ética del discurso del Estado, por el ideal de justicia de la moral social del propio Estado; conlleva la relación vinculante de las bases ético morales de la actualidad, y desde luego, positivarlas.

Es necesario empoderar a la población de este paradigma, y el Estado reconocer las necesidades de la población, el modelo humano de acceso a la justicia requiere de la adopción y desarrollo de habilidades de relaciones intersubjetivas entre la población usuaria y los operadores del sistema de justicia, se trata de comprender, entender, escuchar, te- ner una explicación integral del conflicto entre las partes, incluyendo su dimensión humana- intersubjetiva- de los argumentos y pretensiones de las partes, y lo que esperan estas encontrar y obtener del sistema de administración de justicia.

El paradigma de acceso a la justicia debe medirse por el grado de participación y satisfacción de las pretensiones dirimidas de la población en la construcción de procesos dinámicos, constantes y abiertos que fortalezcan la dimensión subjetiva de justicia, basadas en relaciones de reconocimiento y no de concepciones del liberalismo moderno definidas unilateralmente por el Estado.

Las relaciones intersub-jetivas en el nuevo modelo deberán generar un marco conceptual, político-jurídico de acceso a la justicia, que provenga de la participación de la población y que sienta la bases de la paz positiva, ${ }^{13}$ ciudadanos seguros y confiados dispuestos a reconocerlas y asumirlas como suyas; el solo hecho de la imposición de los ordenamientos jurídicos provoca en sí mismo coerción, sumado a la no participación de los mismos, crea en sus destinatarios rechazo, desconfianza y una poca utilización del mismo para resolver sus conflictos.



13 La paz positiva es la reconstrucción de las competencias humanas para hacer las paces, el reconocimiento de las múltiples y diversas competencias humanas para transformar el conflicto y todo tipo de violencias (Martínez, 2000) 


\section{Una reflexión abierta a manera de conclusión.}

La reflexión siguiente pretende dejar el espacio abierto a enriquecer este enfoque de acceso a la justicia, con sus aportes, sugerencias, posiciones y comentarios propositivos, del que forman parte la dialéctica, un ir y venir de experiencias, la participación y entrega del sentir humano.

La noción de recono-
cimiento del derecho
de acceso a la justicia
que se planteó en este
documento es cambiar la
perspectiva de organización

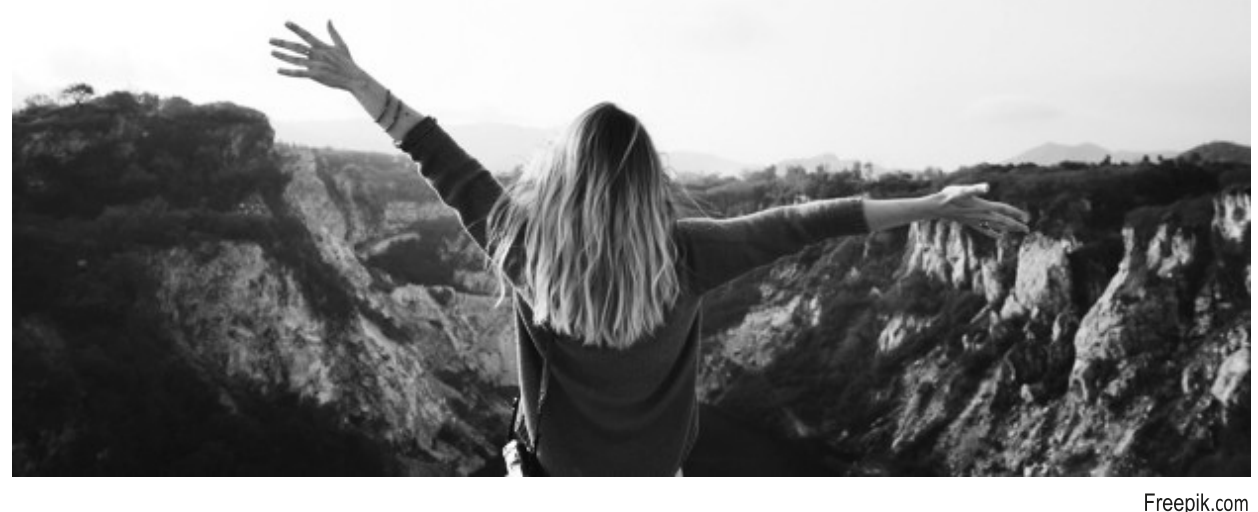
y funcionamiento de las prácticas de exigibilidad que han excluido el sentir humano por el otro, en referencia al poder del Estado cuando vulnera este derecho humano. Desde esta perspectiva el Estado, a través del poder judicial, crea un sistema de justicia de y para seres humanos con garantías definidas y accesibles, provee condiciones para la plena vigencia y protección de los derechos humanos, haciendo sentir a los miembros de la sociedad, libres e iguales en los procesos, procedimientos judiciales y administrativos frente a cualquier reclamo o demanda.

El Estado en esta propuesta además de cumplir su dimensión objetiva, es también parte beligerante y mantiene con la población relaciones reciprocas de reconocimiento, bien definidas, normadas, pone en el centro al ser humano, coadyuva en la satisfacción de sus necesidades de justicia, es un sistema empático, generador de confianza y aprecio en la población, la cual debido a ese reconocimiento e inclusión se sienten parte del sistema de justicia, lo asumen, ejercen y cumplen sus mandamientos, la confianza que el sistema ha ganado en la población provoca que las personas hagan mayor uso del mismo, eso aporta a la paz negativa, al disminuir la

violencia como forma de venganza, y a la paz positiva, porque potencia las múltiples y diversas habilidades de la población que se empodera y desarrolla autogestión ciudadana de sus propias demandas.

La población forma parte de la producción legislativa, jurídica y administrativa del concepto de acceso a la justicia. Creando relaciones intersubjetivas de colaboración y cooperación para adaptarse a los cambios culturales que demandan trabajos conjuntos entre gobernantes y gobernados, es decir, una identidad conjunta.

El nuevo modelo de acceso a la justicia ha de ser un espacio que articule el reconocimiento de las diferencias con el reconocimiento igualitario, creando relaciones sólidas intersubjetivas, entre el Estado y su población, en la autorrealización de las diversas etapas del desarrollo humano, logrando permear en todos los derechos humanos, sin que la mismidad del Estado y de las partes en un conflicto resulten insatisfechas, sino que la otredad resulte ser una herramienta viva para la prevención de la violencia. 


\section{Bibliografía}

1. Arend, Hannah. (2005). «Sobre la violencia». Madrid. Alianza Editorial.

2. CALDERÓN, FERNANDO. (1999). «La Nueva Cuestión Social bajo la mirada del Desarrollo Humano». Bilbao, España. Disponible en: http://www.nuso.org/ upload/articulos/2840_1.pdf Fecha de Consulta: $20 / 12 / 12$

3. Convención Americana de Derechos Humanos.

4. Corporación Latinobarómetro. (2017). «Encuesta realizada por Latinobarómetro un estudio anual de opinión pública»». Disponible en: file:///C:/Users/MARIO/Downloads/ F00006433-InfLatinobarometro2017.pdf Fecha de consulta: 07/10/18

5. Montse Díaz. «Educación Ético-Cívica» $4^{\circ}$ ESO Dep. Filosofía

6. Dyer, W. Wayne. (1997). «Tus Zonas Sagradas». Editorial Grijalbo. México, D.F.

7. Jiménez-Bautista, F. (2012) «Conocer para comprender la violencia: origen, causas y realidad. " Universidad de Granada, España.
8. FRASER, NANCY. (2006). "La Justicia Social en la era de la Política de la Identidad. Redistribución, reconocimiento y participación». Tomado del libro ¿Redistribución o reconocimiento? Un debate político filosófico de Nancy Fraser y Axel Honneth. Ed. Morata. En Revista de Trabajo, Año 4, Número 6 de diciembre 2008. Págs. 83-89

9. HENRICH, DIETER. (1983). «Hegel. Filosofía de Rechts 1819/20». Frankfurt, Alemania.

10. HONNETH, AXEL. (1997). «La lucha por el reconocimientol. Para una gramática moral de los conflictos sociales Barcelona, España. Págs. 114-150.

11. MARTíNEZ GUZMÁN, VICENT (2000): «Saber hacer las paces. Epistemologías de los Estudios para la pazı Convergencia. Revista de Ciencias Sociales, 7 (23), 49-96.

12. UPAZ/GIZ/DIRAJ us. (2014). «El derecho de acceso a la justicial. Un acercamiento al marco de referencia sobre su concepto, sus principios rectores, y su ámbito de protección. 